\title{
Viviendo en el mundo material. Fotografías de indígenas del Desierto de Chile ${ }^{1}$
}

\section{Living in a Material World. Pictures of Natives from the Chilean Desert}

\author{
Pedro Mege \\ Escuela de Antropología, Universidad Academia de Humanismo Cristiano. \\ Santiago, Chile \\ pmege@academia.cl
}

Resumen - Para los constructores chilenos — cronistas, exploradores y etnólogosde la visualidad fotográfica del desierto y el altiplano del Norte de Chile, ésta se expresa, en sus publicaciones, como una materialidad deshumanizada, conformada por una visualidad de lo desértico que expulsa a la humanidad, donde la materialidad se hace dueña de las imágenes, escamoteándola, sustrayendo muy especialmente al indígena. Este trabajo explorará los procesos y mecanismos simbólicos que permitieron tal expulsión y exclusión, en la imagen visual del indígena del Norte de Chile en una serie de publicaciones de especialistas y literatos que tratan sobre el desierto y sus habitantes ancestrales y presentes.

Palabras clave: visualidad fotográfica, indígenas, Norte Grande.

Abstract - For Chilean constructers - chroniclers, explorers and ethnology researchers - of photographic visuality of the Chilean desert and altiplano, images presents itself, in publications, as a dehumanized materiality made by an imagery of the desert that expulses humanity, where materiality gets hold of the images, keeping it a secret so as to subtract, specially, the natives. The following paper will explore the process and symbolic mechanisms that allowed the expulsion and exclusion, in the images, of the natives from the North of Chile in a series of publications and people of letters who deal with subjects such as the deserts and its ancestral and living habitants.

Keywords: photographic visuality, natives, Norte Grande.

1 Este trabajo es producto del Proyecto Fondecyt núm. 1060681 «La representación de la alteridad: Fotografías de los indígenas del Norte Grande (1911-1990)». Responsable: Margarita Alvarado. 
I'm living in the material world

Living in the material world I hope to get out of this place.

George Harrison, 1973

\section{PRESENTACIÓN}

Para este trabajo hemos seleccionado las obras de los siguientes autores: por un lado, dentro de la literatura y el género de los relatos de viaje, Andanzas por el desierto de Atacama (1969) de Salvador Reyes; por el otro, dentro de la difusión científica, Cultura atacameña (1978) de Bente Bittmann, R.P. Gustavo Le Paige S.J. y Lautaro Núñez; y Pueblos del Desierto, entre el Pacífico y los Andes (2001) de Calogero Santoro, Eliana Belmonte, Vivien Standen, Juan Chacana, Jorge Hidalgo, Luis Briones, Liliana Ulloa y Héctor González. Esta selección de las obras obedece al fuerte impacto que han producido en el imaginario relacionado a las temáticas trabajadas — según público en general y especialistas - sobre los habitantes del desierto y el altiplano chileno; sumado a esto, su alta circulación y la notoriedad de sus autores. Obedecen, además, a tres períodos de instalación del imaginario del «indígena del desierto»: primero, incipiente inicio en los años sesenta, segundo, instalación en los setenta; tercero, consolidación desde los años noventa hasta el presente siglo. Son publicaciones con una clara intención de difusión científica, donde la fotografía juega un papel protagónico por el lugar que ocupa en la estructura de las obras, su vinculación con los textos y su función de ilustrar visualmente ciertas temáticas en cada uno de éstos.

La instalación de este imaginario tiene que ver con una persona excepcional, un investigador y profeta desterrado a las profundidades del mundo por sus ideas neoevolucionistas. Gustavo le Paige, un belga jesuita proscrito, que a partir de la nada fue creando un mundo de proporciones cósmicas. Tanto Salvador Reyes como Bittman (y los otros autores del libro) se inspiran en este pensador y gestor vigoroso de los imaginarios el Norte Grande de Chile. Es más, Bente Bittman y Lautaro Núñez se hacen acompañar de él en una peregrinación hacia el mundo que él descubrió y creó, dándole una dimensión que rebasó los modestos márgenes del desierto y de, particularmente, el Oasis de San Pedro de Atacama. Este emisario de las nuevas ideas es quien moviliza las concepciones sobre los primeros hombres del desierto y sus actuales residentes. Además, crea un puente imaginario entre ambos en base a su actividad arqueológica, etnológica y pastoral. Salvador Reyes nos entrega sus impresiones y una semblanza del maestro profeta del Oasis de San Pedro de Atacama:

Pienso en los monjes medievales y del Renacimiento, que iban a pie, comiendo que iban a pie, comiendo cualquier cosa o no comiendo, durmiendo en donde los cogía la noche, de un convento a otro, en busca de peregrinos que iluminar, de gentes humildes a quienes socorrer, indiferente a los bienes humanos, con el alma puesta en Dios, pero con el cerebro en la tierra, observando los fenómenos naturales, meditando; pienso en esos grandes 
vagabundos alegres que cantaban la belleza del mundo, poetas a veces, otras veces sabios que se encerraban en las misteriosas bibliotecas a escribir gruesos folios, completamente olvidados de si mismos, sumergidos en el conocimiento y en la caridad como en un agua transparente llena de cielo. Pienso en ellos y me pregunto si su raza ha terminado; pero me viene el recuerdo del padre Teilhard de Chardin, del abate Breuil...

Y he aquí que encuentro el retrato del padre Teilhard de Chardin en San Pedro de Atacama. Es una fotografía pequeñita, recortada de algún periódico y puesta en un modesto marco, [e]stá allí sobre la mesa cubierta de papeles, de minerales, de huesos fosilizados, de juguetes rotos, en la que trabaja el padre jesuita Gustavo le Paige (1969: 159-60).

Solo en cuatro años el Padre Le Paige había desplegado toda su potencia creativa y activa, fundando un particular Museo Arqueológico y Arqueológico que activó la imaginación de muchos especialistas y aficionados. La descripción que hace Salvador Reyes de la mesa de Le Paige es significativa, en ella se encuentran los elementos que concurrirán en el futuro de las mentes de sus seguidores — confesados e inconfesos- la presencia de una objetualidad sólida y dura: minerales, huesos fosilizados y juguetes rotos. Es la presencia del hombre desde su parte más dura, es su parte mineral, y será desde esta presencia material que sus seguidores encontrarán el marco referencial inconscientemente obligado en la construcción de los hombres de ese desierto y de los desiertos aledaños (lámina1).

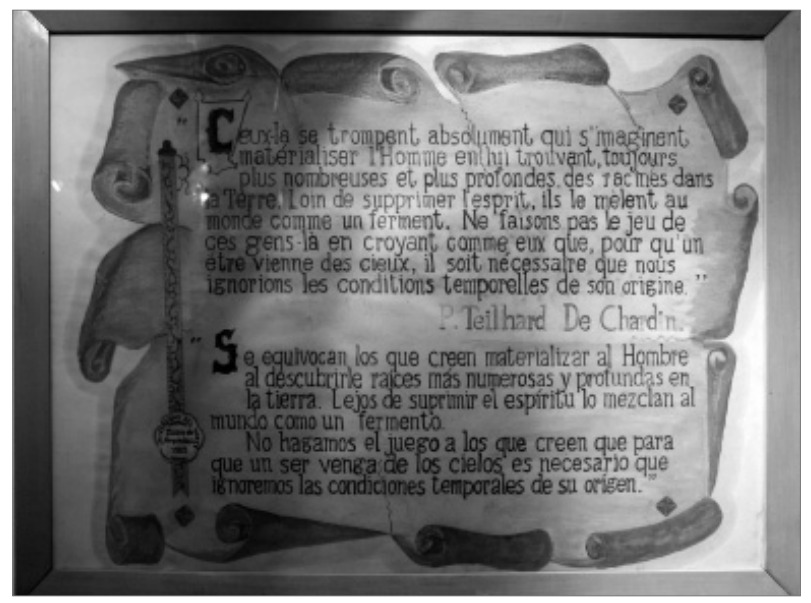

1. Fotografía de un cuadro con una cita de Teilhard de Chardin que forma parte de una recreación de la pieza del Padre Gustavo Le Paige, en el Museo Arqueológico RRPP Gustavo Le Paige, San Pedro de Atacama, Región de Antofagasta, Chile.

\section{FUERA DE CUADRO}

Desde esa materialidad fundante de Le Paige pasamos de un imaginario del coleccionar materiales a registrarlos en una tecnología que, por su eficacia y posición nos resulta difícil analizar. La fotografía en su poderoso mecanismo de representación nos avasalla críticamente y debemos hacer un esfuerzo especial de concentración para poder estable- 
cer estrategias del imaginario. De la cosa le paigeniana pasaremos a su registro como expresión de las culturas del Desierto del Norte de Chile.

Claro, el hombre ha creado lo que vemos en las imágenes fotográficas, pero por un mecanismo misterioso los indígenas del desierto han sido desplazados del cuadro, del "encuadre", definido por Deleuze como: "la determinación de un sistema cerrado, relativamente cerrado, que comprende todo lo que está presente en la imagen» (2001: 27. Cursiva del autor). Han quedando fuera del marco, "fuera del campo»: "no se trata de una negación [...] remite a lo que no se oye [en este caso en particular, no se lee] ni se ve, y sin embargo está perfectamente presente» (32). Evidentemente los autores no se esfuerzan en un ejercicio de «la negación», no hay una estrategia de ocultamiento, sino del relegamiento a ese otro campo fuera del cuadro, lo «que da fe de una presencia más inquietante, de la que ni siquiera se puede decir ya que existe, sino mas bien que insiste» o 〈subsiste»» (35). Apuntaremos en nuestro análisis a esta insistencia y subsistencia del indígena del desierto desde el «desencuadre».

Demostraremos cómo en estas publicaciones centrales sobre el Norte de Chile y sus habitantes originarios, este indígena queda relegado por una materialidad, principal y sintomáticamente, por sus propios productos materiales, que nos conectan con ese otro campo de la ausencia, ya que «todo sistema cerrado [encuadrado] es también comunicante, [...] siempre hay un conjunto más grande o bien otro con el cual el primero forma uno más grande» (33). El enmarque lo escamotea, al indígena del desierto, dejándolo en este «fuera de campo», pero que lo incluye en un «todo» (ibid.)

\section{TERRITORIALIDAD, NACIONALISMO Y RACISMO: LA IMAGEN INCIERTA DEL INDÍGENA DEL NORTE GRANDE}

Tal vez el Chile Republicano Temprano, se imaginó a sí mismo como un territorio, «mi Patria», con un "Centro», al cual había que anexar una Araucanía que estaba geopolíticamente pendiente por el Sur, y no calculó la futura anexión de los territorios peruanos y bolivianos al norte de Copiapó, al norte del Descampado de Atacama, que descontrapesó su imaginario topológico.

Lo que se tradujo, probablemente, en que el imaginario de lo nacional los indígenas del Norte Grande no ocuparan un lugar como los originales y obligados ancestros de la población chilena mestiza, de «lo chileno», lugar que sí ocuparon los araucanos, como el antecedente racial, de los antecesores «raciales» del pueblo chileno. Esta exclusión «racial» de los Indígenas del Norte Grande podría, quizás, explicar la ausencia de una «visualidad $»^{2}$ de ellos en ciertas publicaciones sobre «ellos».

Pero si se escribe sobre ellos, ¿por qué no se los muestra en la fotografías, como pasa con los araucanos y fueguinos ${ }^{3}$ ? Aclaremos, se los muestra de una forma indirecta, en

\footnotetext{
La «visualidad», según Rose, referida a: "to the way in which vision is constructed in various way» (2007: 2).

3 Es sintomática la publicación homóloga de difusión ministerial de Carlos Aldunate del Solar en La cultura Mapuche (1978), donde el araucano es profusamente mostrado; o cualquiera de los fueguinos, como la de Pedro Mayorca Martínez en Costumbres y extinción de los indios del Extremo Austral, 1973, donde sucede otro tanto.
} 
una «a través de» de paisajes, naturaleza y particularmente su cultura material, como ya se dijo. Encontramos en el texto la presencia de ellos, y de forma directa la alusión de ellos en el texto que acompaña a la fotografía de su visualidad relegada, de su «fuera de cuadro».

Los autores que revisaremos en este trabajo, por alguna razón, excluyeron concienzudamente las imágenes fotográficas de indígenas en sus textos; fotografiaban todo en el desierto, con gran minuciosidad, pero esquivaban al indígena con la misma dedicación. Si hay algún fundamento histórico a esta práctica lo dejaremos por el momento pendiente, o mejor, lo relegaremos definitivamente a los historiadores.

\section{EL LAPSUS IMAGO. LA INSTALACIÓN VISUAL SUPLANTADA DEL INDÍGENA DEL DESIERTO}

En el psiquismo no existe nada arbitrario ni indeterminado.

\section{Sigmund Freud, Psicopatología de la vida humana}

Seguiremos un esquema de instalación de las imágenes fotográficas reproducido por los diferentes autores, que se relaciona con una secuencia de temas, los cuales se ilustran por medio de la fotografía. Este esquema de secuencia de imágenes fotográficas tiene, de manera evidente, un fondo proyectivo que lo organiza. Rapta al significante del indígena y lo suplanta con imágenes parciales de su totalidad — como productos culturales, flora, fauna y paisajes-, totalidad que llamaremos «desierto». Éste supondrá unos tiempos y unos espacios, unos elementos y unas señales de lo humano, dejadas como rastros de ese significado «raptado».

Nuestro programa tiene algo de lacaniano. El programa que se traza para nosotros es entonces saber como un lenguaje formal determina al sujeto (Lacan, 1990:36).

En el contexto de las obras que hemos elegido, éstas se constituyen a partir de un doble lenguaje formal, escritura y fotografía. Una particular sintaxis de las visualidades que nos determinaría un «sujeto", que aquí es una comunidad: los habitantes del «desierto".

\section{PRESENTACIÓN DE LAS IMÁGENES, PORTADAS}

El análisis que realizaremos parte con sus portadas, con unas imágenes fotográficas que nos van ir indicando, desde su presentación, cómo se van a ir instalando las representaciones de lo indígena en estas tres obras desde sus inicios, desde sus portales, desde sus portadas. Salvador Reyes abre con las ruinas arqueológicas en su portada de Andanzas por el Desierto de Atacama; por su parte, los autores de Culturas del Desierto lo hacen con piezas arqueológicas; mientras que los de Pueblos del Desierto, con otra pieza arqueológica. En estas dos portadas últimas está presente la palabra «desierto» en los 
títulos, aludiendo, desde ya, a una ausencia de lo vivo, y por extensión, de la humanidad, preparando los significantes para el siguiente contexto ${ }^{4}$ de la obra.

Se habla de "pueblos» y de "cultura» sin alusión a una etnia específica, que por lo demás son muy pocas, y casi exclusivamente aimaras. Es cierto que las publicaciones, al menos las más técnicas, intentan abarcar arqueológicamente a todas desde muy temprano, pero hay una cierta indicación, un solapado intento por dirigir la mirada hacia una abstracción del sujeto, "cultura», y a unos sujetos indiferenciados, "pueblos».

Sospechamos un cierto entramado ideológico en el nombrar de nuestros autores, una «resistencia», en la instalación de un indígena como sujeto de una presencia activa. Siguiendo a Slavoj Žižek entendemos que la:

materialización de la ideología en un objeto concreto exterior pone en evidencia los antagonismos inherentes que no pueden ser reconocidos por la formulación ideológica explícita: es como si la edificación ideológica, para poder funcionar «normalmente», debiera obedecer a un "diablillo perverso» y formular su antagonismo inherente en la exterioridad de su existencia material (2005: 12).

Materialidad desértica presente como objeto exterior, de "una ideología $»^{5}$ que preferimos referir al plano inconsciente del deseo, del desplazamiento del «sujeto-comunidad». Para Freud el deseo, Wunsch, tiene una acepción algo distinta que la del castellano, no se identifica con la necesidad nacida de un estado de tensión interna y que encuentra su satisfacción por una acción específica. Se trata de un fenómeno de orden simbólico, de la búsqueda de un significante; entonces se trata de «la búsqueda del objeto en la realidad, que se halla totalmente orientada por la relación con signos. La disposición de estos signos constituye la fantasía, correlato del deseo»(J. Laplanche y J. Pontalis, 2005: 97). Preludio de una evidencia que queda demostrada por las fotografías de la portada — de piezas y ruinas arqueológicas como fantasía- dejándonos entrever, ya inicialmente, un deseo de «desierto» (láminas 2, 3 y 4).

4 Tomaremos el significado de contexto en su acepción lexicográfica, es decir, como entorno lingüístico [en este caso, no sería lingüístico, sino, que icónico] del cual depende el sentido y el valor de una palabra, frase o fragmento considerados; entorno físico o de situación, ya sea político, histórico, cultural o de cualquier otra índole, en el cual se considera un hecho. Esta vinculación solidaria de los entornos semiótico, situacional y físico, lo que nos daría el sentido de «desierto" para nuestros autores.

5 No nos parece justo hablar de un aparato «ideológico» en nuestros autores, supondría la constatación de una intencionalidad estratégica en sus discursos, podríamos decir aparato de discriminación u ocultamiento, y no es eso, es más bien un sutil juego de impresiones «en el» deseo de una perpetuación del desierto. Volveremos sobre este punto más adelante. 
I 84

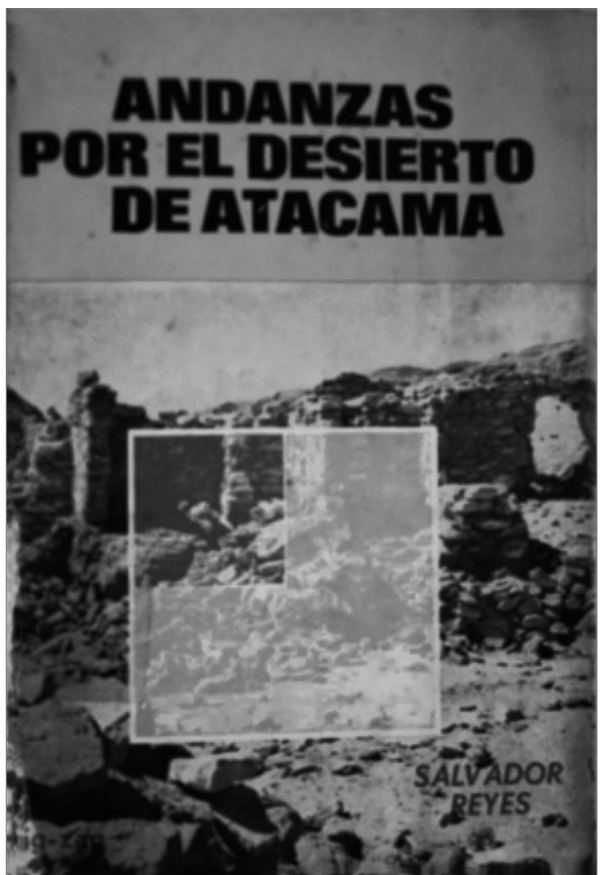

2. Portada texto Andanzas por el Desierto de Atacama (1969).

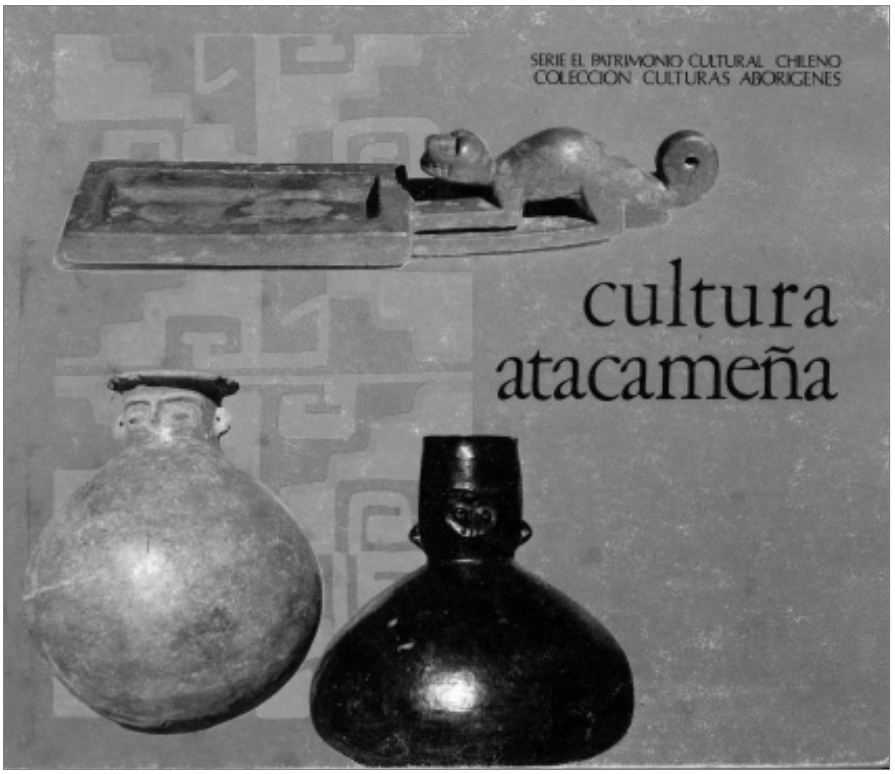

3. Portada texto Cultura Atacameña (1978). 


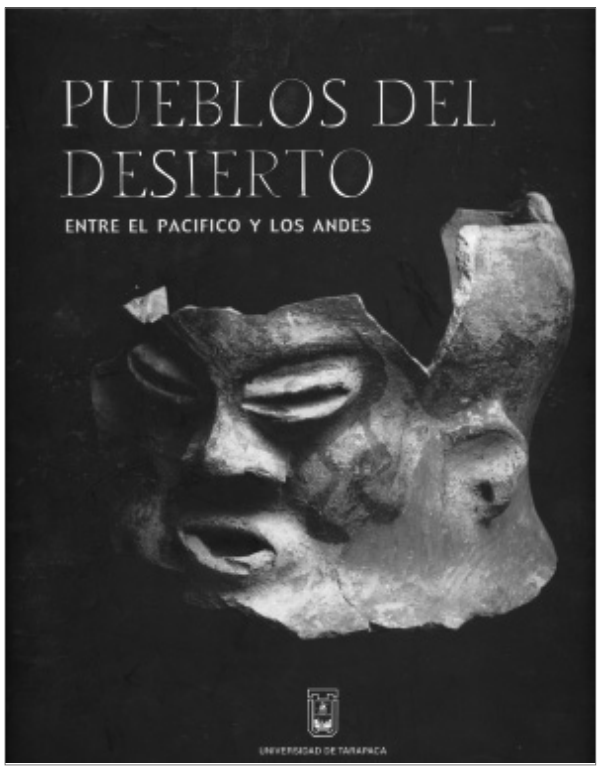

4. Portada texto Pueblos del Desierto, entre el Pacífico y los Andes (2001).

\section{TIEMPOS Y ESPACIOS DEL DESIERTO}

Dos categorías que hemos considerado como la base de la construcción de estos imaginarios del desierto y sus indígenas, son la del tiempo y el espacio. Arrancaremos desde la sabida proposición de Benjamín Lee Whorf sobre la importancia discursiva de ambos elementos, que opera desde la estructura profunda de la lengua, en la configuración de los significados básicos de cualquiera mundo-visión.

Creo que es gratuito suponer que un hopi que solo conoce su lengua y las ideas culturales de su propia sociedad, tiene la misma noción que nosotros sobre tiempo y espacio, noción que a menudo se suponen intuiciones universales. En particular, un hopi no tiene una noción o intuición general de TIEMPO como un continum que transcurre uniformemente y en el cual todo el universo en su conjunto marcha a un mismo paso desde un futuro, a través de un presente hacia un pasado, o, para darle la vuelta a la imagen, en el que el observador es arrastrado por la corriente de la duración, alejándose constantemente de un pasado, hacia el futuro (1971: 57).

Whorf nos amplía el sentido y compresión de la relatividad espacio-tiempo (58). En el caso que nos ocupa, las maneras cómo disponen el tiempo y los espacios en sus obras nuestros autores, nos dirigen una peculiar manera de ver tiempos y espacios, en donde el pasado se actualiza como una especie de presente transitivo, se habla de los "Aimaras contemporáneos» al final del libro (Santoro et. al., 2001: 110-5), en una indicación evidente de que la actualidad es rescatada al final de los tiempos, los tiempos contemporáneos.

Aplicaremos la propuesta whorfiana para los iconos que operan en estas publicaciones, que nos mostrarán una particular estrategia de la imagen fotográfica en relación a los sentidos del tiempo y el espacio. 


\section{Tiempo:}

Lo primero que se descubre es una sobrevaloración de lo arcaico sobre lo contemporáneo - arqueo-lógico, significante de lo arcaizante; de lo pre-histórico, significante del objeto-, sobrevaloración de lo pretérito sobre lo contemporáneo, el antes de la presencia del autor en el "desierto" (Reyes, 1969) o lo arqueológico sobre lo etnológico (Bittman et. al., 1978; Santoro et. al., 2001). Aunque a estas alturas sabemos que la intuición antropológica es la última en una mente occidental, y de la fuerte formación inclinada a lo histórico-arqueológico de nuestros autores, lo que no es suficiente explicación para la ausencia de fotografías etnográficas del indígena del desierto, ya que los textos sobre ellos siempre están, aunque en los márgenes del relato total, no así las fotografías sobre ellos, están fuera del los marcos (láminas 5 y 6).

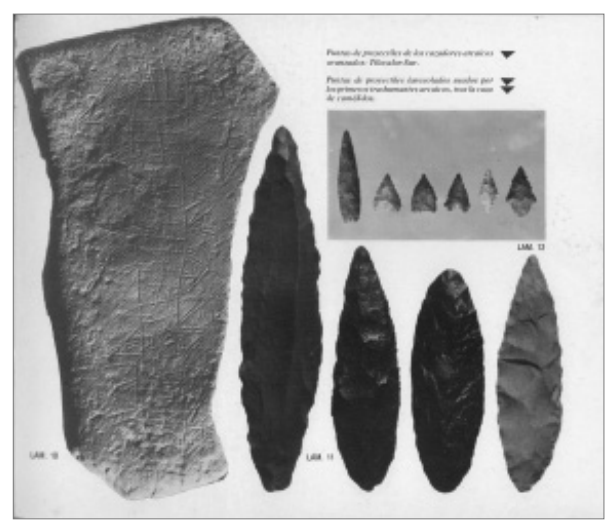

5. Cultura material en Cultura Atacameña (1978).

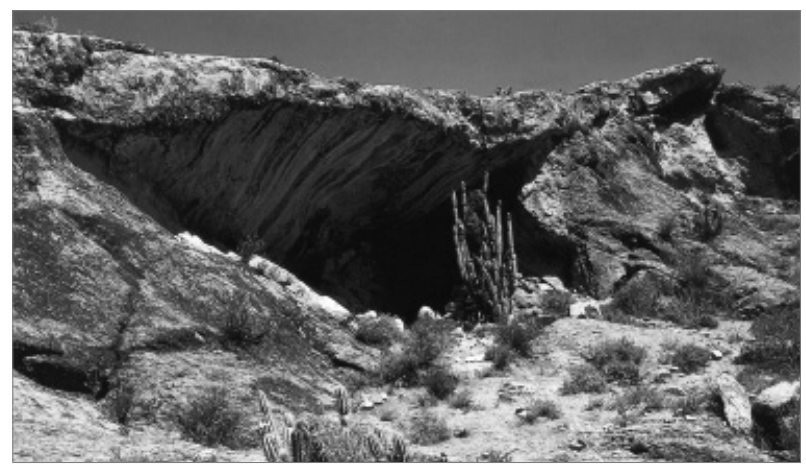

6. Cultura material en Pueblos del Desierto, entre el Pacífico y los Andes (2001).

\section{Espacio:}

El paisaje inaugura estas publicaciones de manera majestuosa, «realzando» — como nos lo diría Thomas Mann- el desierto como lugar, en una serie de claves muy estables, que nos repiten sus elementos compositivos, en una especie de aliteración de éstos. Por 
ejemplo, en una panorámica clásica los autores nos proponen una estructura del paisaje en base a ciertos elementos recurrentes que se articulan solidariamente para conformar un paisaje del desierto, como una matriz determinada (Santoro, et. al: 10; Bittman, et al.: 9).

Podemos hablar de una estructura elemental del paisaje que, con pequeñas variaciones, nos instala recurrentemente los mismos componentes básicos (figura 1):

Figura 1: Estructura elemental del paisaje

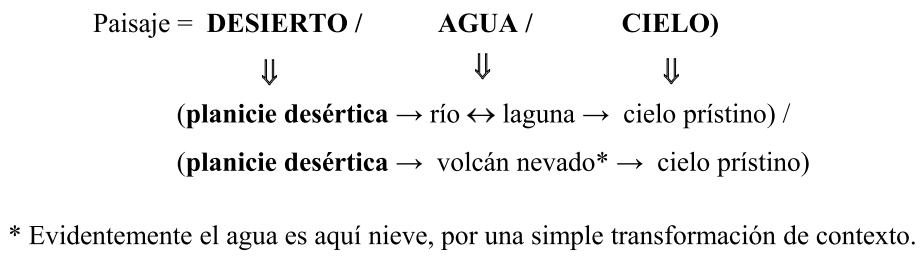

La invitación a lo paisajístico es recurrente, produciendo un efecto encantador y «exotizante», entendiéndolo según Peter Mason como el proceso de lo exótico: "Lo exótico nos pertenece como cultura occidental, y lo descubrimos en esos seres distantes, ajenos, intimidantes y magnéticos que llamamos nativos. Nuestro discurso los atrapa, parcialmente, y nos los devuelve, de manera especular, como seres de lo exótico» (1998: 23). Más aún, la exotización requiere de un necesario proceso de análisis crítico, porque como dice Mason:

El sitio de generación de lo exótico es una supuesta realidad extralingüística, sino que un sitio representacional. En otras palabras, no está originalmente localizado en algún lugar y secundariamente reflejado en una representación. Más bien, es el producto de los muy representados, lo producido por el proceso de exotización. [...] Si lo exótico no es encontrado, sino que es más bien producido, estamos definitivamente obligados a decir algo sobre el sitio y la modalidad de su producción (159-60).

Este paisaje exotizado como lugar de representación, este «desierto» «es un producto de lo muy representado", y por lo mismo se nos fragmenta en diferentes subcategorías complementarias, en un esfuerzo de totalidad de lo representado:

1. Paisaje natural, ilimitado, sobrecogedor, místico, «imponente», «desafiante»: con la total ausencia del hombre en las fotografías.

2. Paisajes de ruinas, la presencia escamoteada del hombre: huellas, de la presencia ausente del hombre.

3. Paisajes cultivados y empastadas, la marca ostensible del hombre, en paisajes que ha construido o controlado, cuya presencia ha sido doblemente escamoteada: del sujeto oculto, visible en su obra sobre el «Desierto", su significado "desplazado» (Freud, 1996: 10); y el significante robado, al lugar de ese significante, en el Desierto; es decir, «la preeminencia del significante (desierto) sobre el sujeto» (Lacan, 1990: 32), ya que, esos paisajes labrados remiten, por asociación a la totalidad de la publicación, a un pasado de esa humanidad presente. 
Enfrentamos el problema como un lapsus, como el asunto del «sustito erróneo» (Freud, 1996: 10). Este lapsus de nuestros autores está referido a lo que Jaques Lacan definió como «la insistencia de la cadena significante» (1990: 5), a la persistencia de una actividad representacional, inconsciente, la exclusión de la imagen fotográfica del indígena, dentro de un ámbito de la significación que lo contiene, en este caso: «el desierto del indígena sin él», su espacio sin su imagen (láminas 7 a la 13).

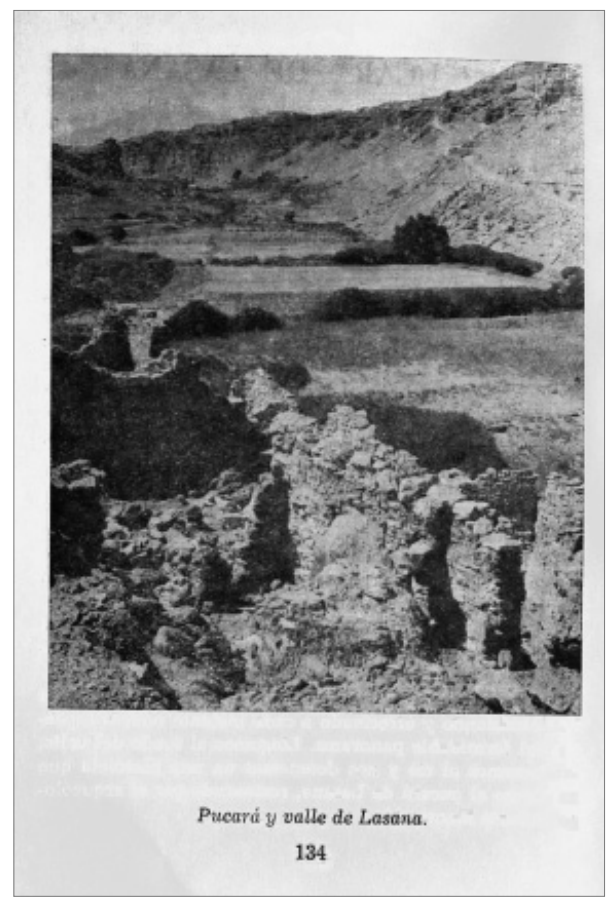

7. Espacio. Pucará y valle de Lasana, fotografía que integra los tres paisajes: cultivados, naturales y de ruinas. Andanzas por el Desierto de Atacama (1969).

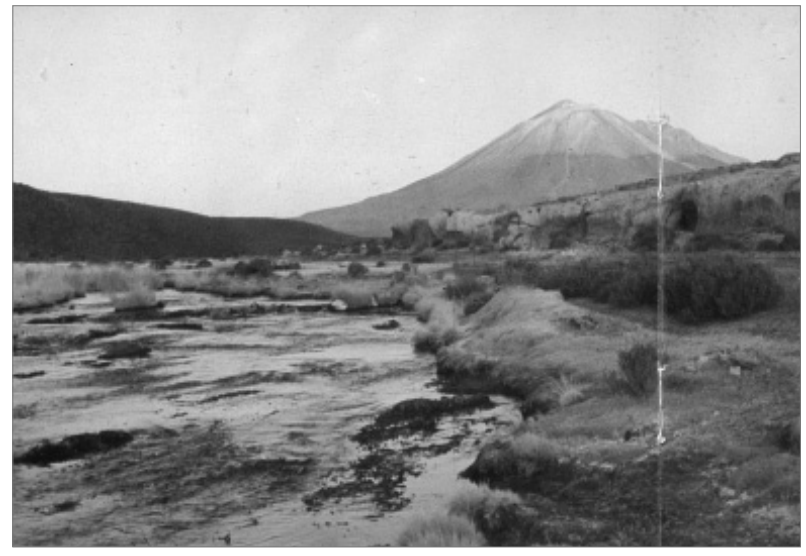

8. Paisajes naturales en Cultura Atacameña (1978). 


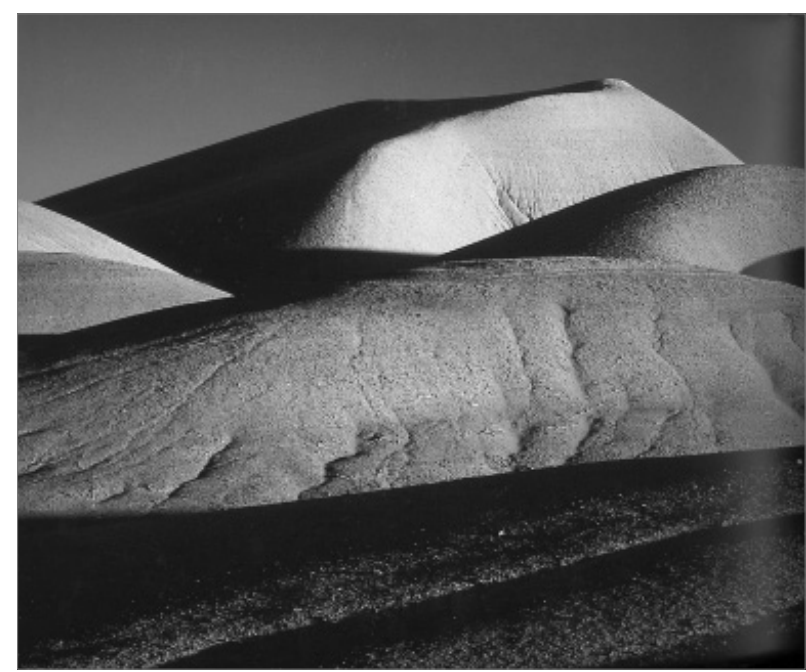

9. Paisajes naturales en Pueblos del Desierto, entre el Pacífico y los Andes (2001).

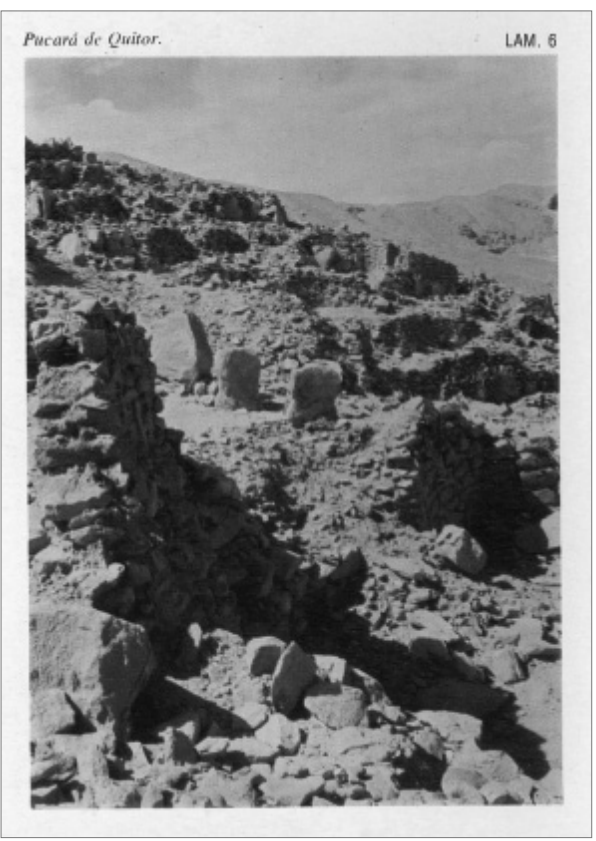

10. Paisajes de ruinas en Cultura Atacameña (1978). 


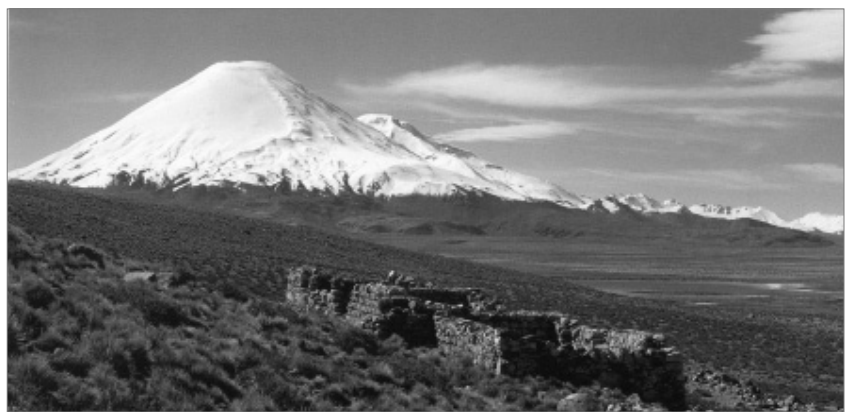

11. Paisajes de ruinas en Pueblos del Desierto, entre el Pacífico y los Andes (2001).

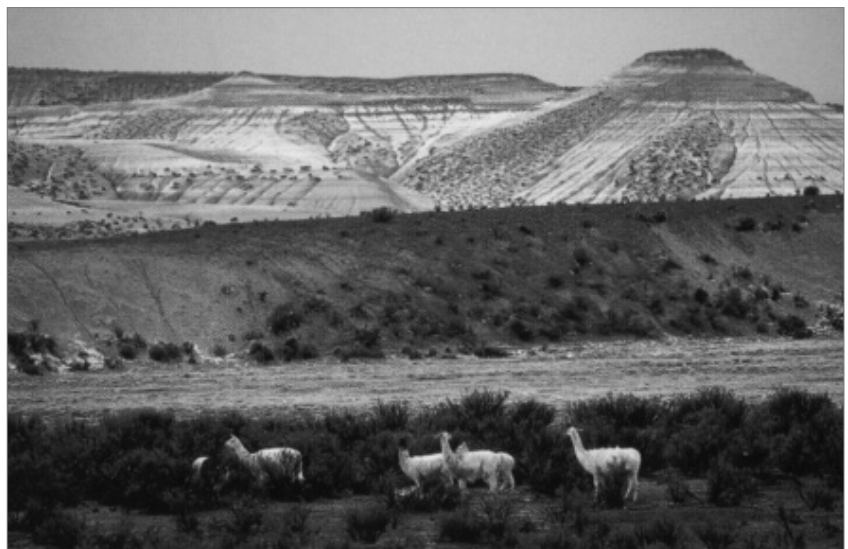

12. Paisajes cultivados, en Pueblos del Desierto, entre el Pacífico y los Andes (2001).

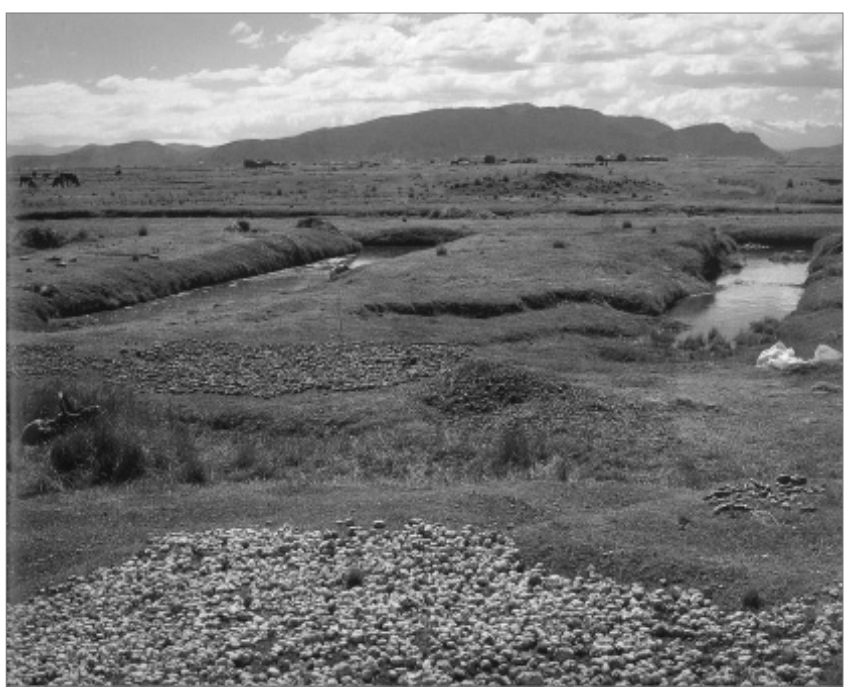

13. Paisajes cultivados, en Pueblos del Desierto, entre el Pacífico y los Andes (2001). 


\section{Plantas y animales:}

Es el retrato de la precariedad de la existencia, la existencia heroica de la naturaleza en la sequedad. Ésta se presenta en fotografías sobre animales y plantas del desierto. Contraste llamativo, en el lugar de lo inerte resalta la vida expresada en plantas y animales heroicos del desierto. Los animales y plantas complementan los paisajes y son lo vivo. Provocando un efecto inverso al de un registro confiable, al mostrar tantas plantas y animales da la sensación de que el desierto estuviera más habitado por lo vivo de lo que lo está, efecto de la abundancia donde no la hay (láminas 14 a la 17).

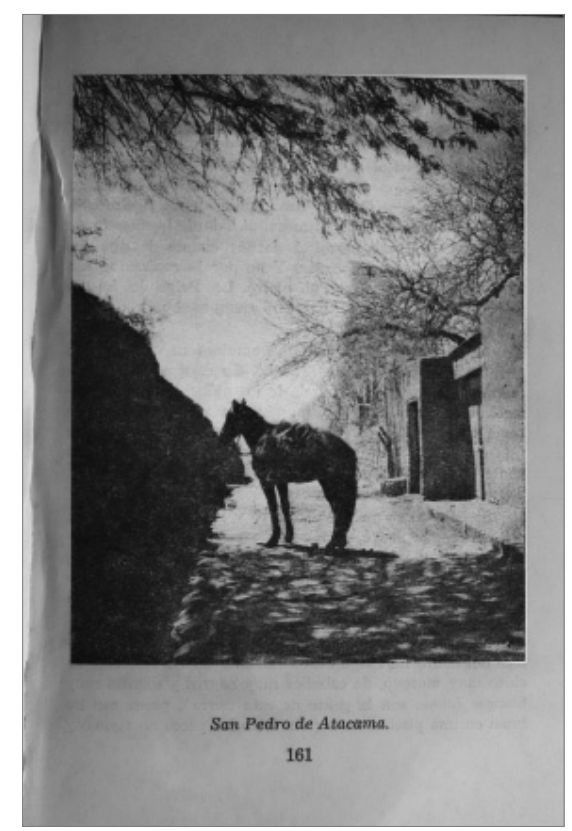

14. Animal en Andanzas por el Desierto de Atacama (1969).

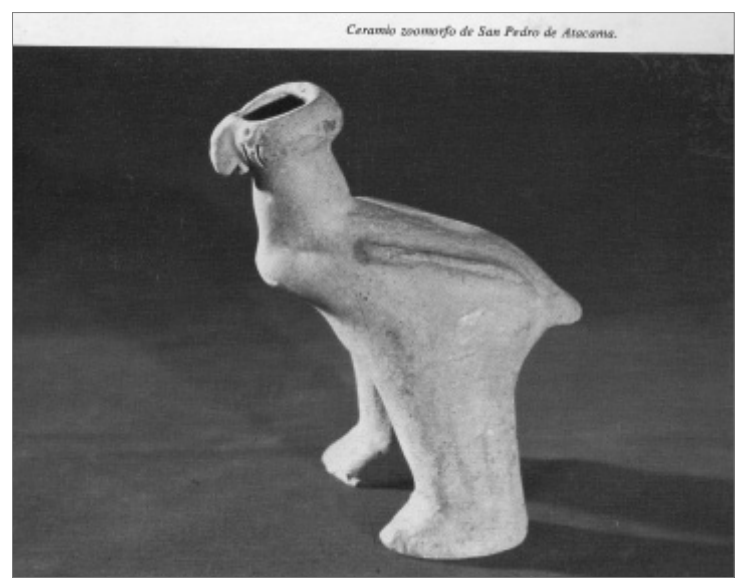

15. Animal en Cultura Atacameña (1978). 


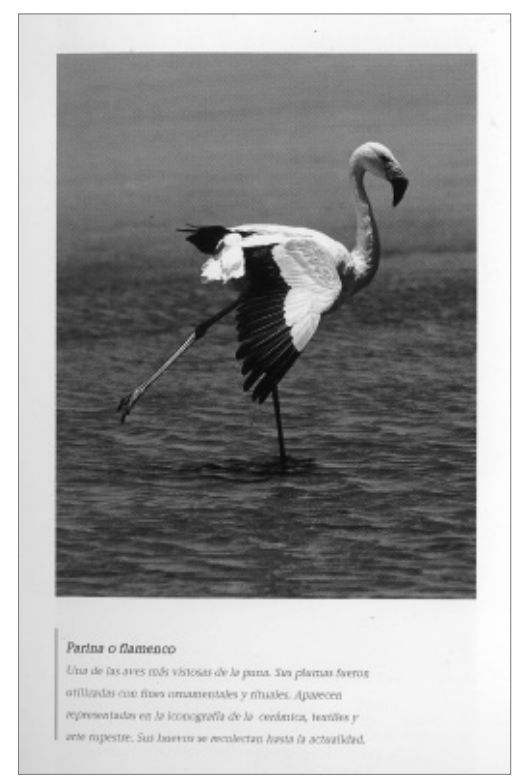

16. Animal en Pueblos del Desierto, entre el Pacífico y los Andes (2001).

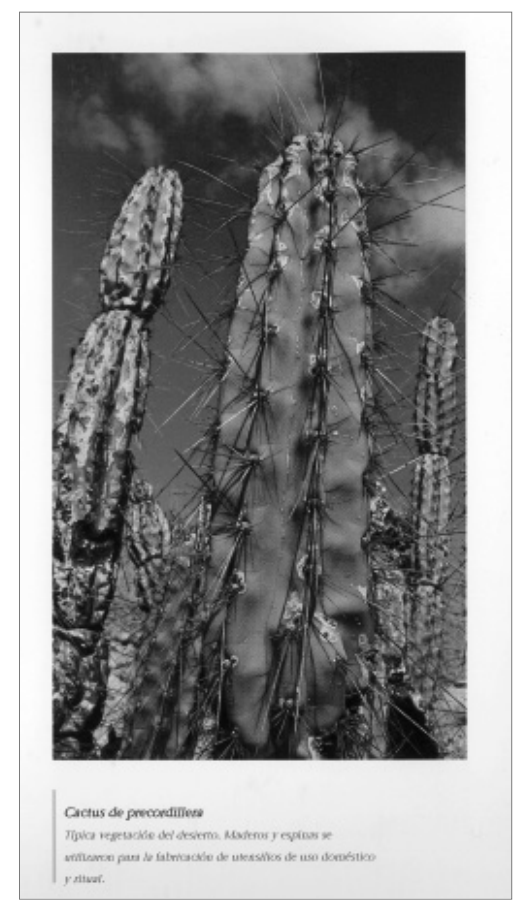

17. Planta en Pueblos del Desierto, entre el Pacífico y los Andes (2001). 


\section{LA HUELLA DEL INDÍGENA, EL INDÍGENA SUPLIDO:}

La preeminencia del objeto material de la humanidad sobre la persona, que se expresa en la fotografía por un reemplazo total del hombre por la tecnología realizada traducida en artefactos e instrumentos.

\section{La cultura material:}

Claramente el desierto, como preservador de la cultura material abruma, su sequedad y desolación, obliga a nuestros autores a un «fetichismo» exquisito del vestigio.

Terminológicamente debemos diferenciar las dos maneras más habituales de entender el fetichismo: la marxista y la freudiana.

En el caso de El Capital, la mercancía, en el mercado, aparece dotada de un valor propio, el precio. Pero ese precio de mercado oculta el costo de producción, el tiempo de trabajo por operarios para lograr el resultado. Los bienes entran en el mercado y tienen un precio que fija la accesibilidad y competencia, en cualquiera tipo de arreglos o prioridades que establezcan los dueños de los medios de producción y de la demanda, creada por la propaganda o espontánea, de esa mercancía.

Lo que oculta es el costo de la producción, o sea el trabajo que los operarios cumplen para producir un bien (Echavarren, 1997: 10-1).

No es en el sentido marxista que tomaremos la noción de fetichismo, sino freudiano, que tiene que ver con la representación del deseo en un objeto, que reemplaza a sujeto del deseo. Marcel Mauss ya advirtió tempranamente que «el objeto que sirve de fetiche, [...] no es nunca un objeto cualquiera, elegido arbitrariamente, sino que es siempre definido por el código de la magia o la religión» (1970: 87).

El objeto comandando a los vivos, el reemplazo de lo que no se encuentra - no se ve-, por un objeto afín a éste, próximo, sometido a un proceso de «desplazamiento» Verschibung (Laplanche \& Pontalis, 2005: 98-100). En el fondo se quiere mostrar al «yo»-indio, pero se muestra su «objeto»-producción material, sus vestigios arqueológicos (Freud, 1993: 10).

Es un fetichismo tan explícito por la cosa material, que incluso se habla de arte, resignificando de manera fuerte a ciertos objetos: el capítulo "Arte en el desierto", de Luis Briones y Liliana Ulloa (en Santoro et. al., 2001), y la delatadora expresión de "no hay expresiones <artísticas> [en la actualidad], las que fueron reemplazadas por una uniformidad artesanal» (en Bittman, 1978: 46). Al poner los autores entre comillas «artísticas〉, son inclusive conscientes de su proyección fetichista, lo que no deja lugar a dudas sobre esta hipervaloración del objeto especial, único, "artístico" del pasado, que fue pervertido por la artesanía actual, actualidad de un indígena ausente.

La materialidad se expande profusamente por los objetos deshumanizados: líticos, cerámicas, metales, maderas y textiles; utensilios y artilugios de todo tipo y arquitectura desolada, mostrando por la "cosa», al sujeto. En el caso de nuestros autores «lo que el fetiche objetiviza es «mi verdadera creencia〉, el modo en que las cosas «realmente me parecen» (Žižek: 144, 2005). ¿Podría aparecer el Desierto sin una imagen de sus indígenas, solo de sus arqueológicas representaciones? (láminas 18 a la 21). 


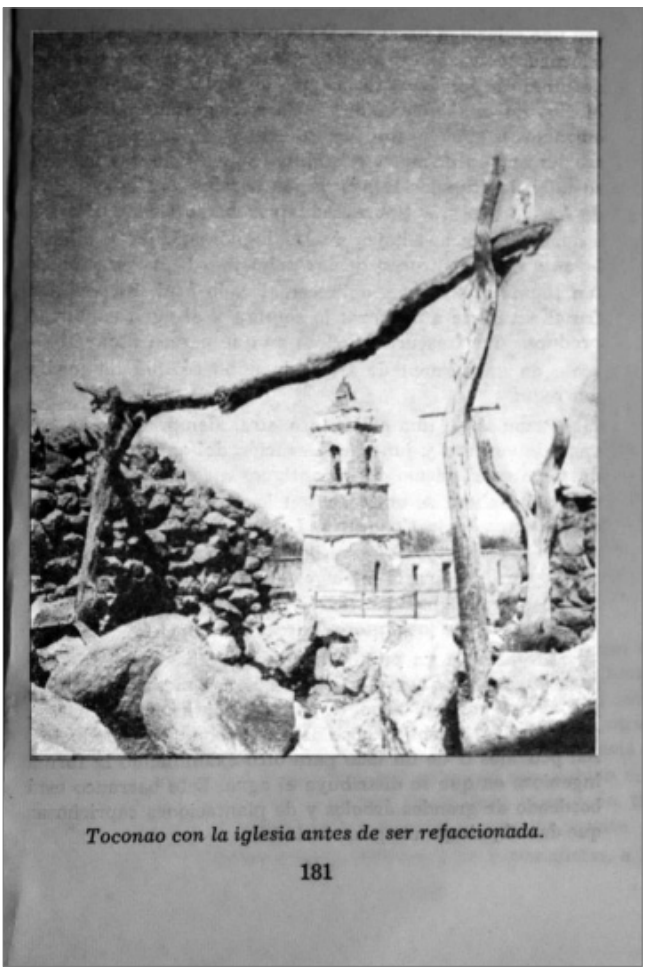

18. Cultura material en Andanzas por el Desierto de Atacama (1969).

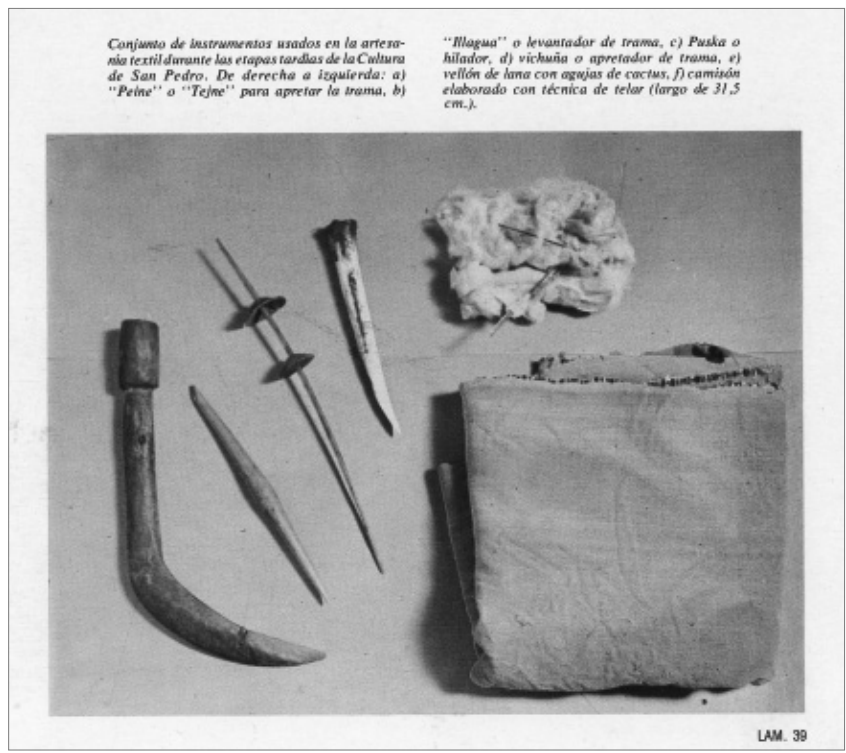

19. Cultura material en Cultura Atacameña (1978). 


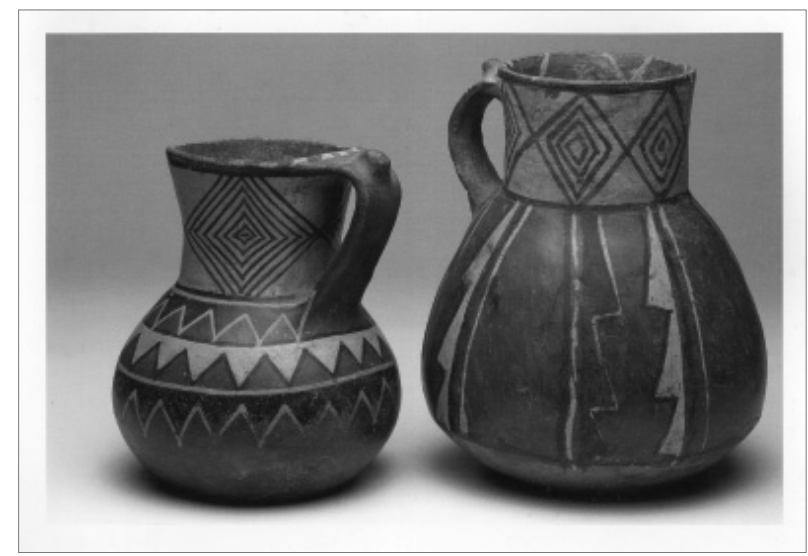

20. Cultura material en Pueblos del Desierto, entre el Pacífico y los Andes (2001).

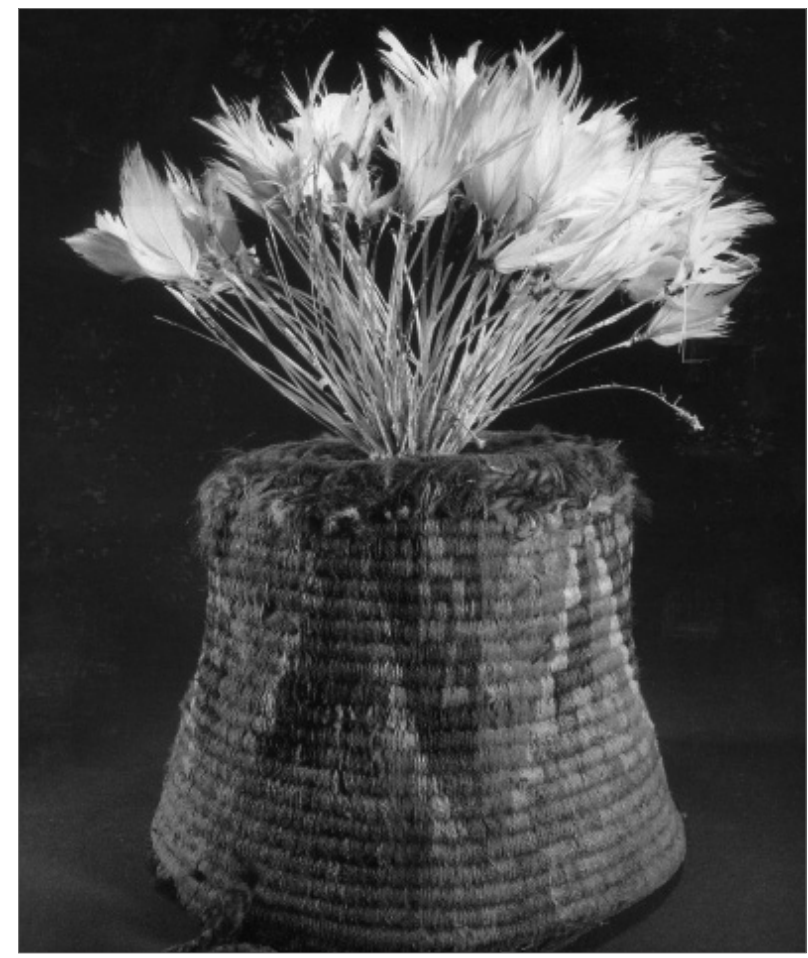

21. Cultura material en Pueblos del Desierto, entre el Pacífico y los Andes (2001).

\section{Hombres vegetales y minerales}

La materialidad del hombre, su sustancia semiótica, sufre un reemplazo en su condición característica, la de ser blanda, elástica y degradable: carne; pasando a ser dura, rígida y perenne: madera, cerámica y metal. Cambiándole su durabilidad, se hace eterna, se fosi- 
liza y su tiempo se «arqueologiza». Esto es muy indicativo de los procesos semióticos que sufre la presencia humana en estas construcciones textuales. Como el hombre no puede presentarse en su presente, es decir, en su carne, se transmigra hacia una materialidad más dura que lo representará en ausencia. Reemplazo radical de lo presente, imagen del indígena andino, por un indígena pasado que se hace presente en una materialidad, substancialidad del significante, que lo remplaza ${ }^{6}$ (láminas 22 y 23).

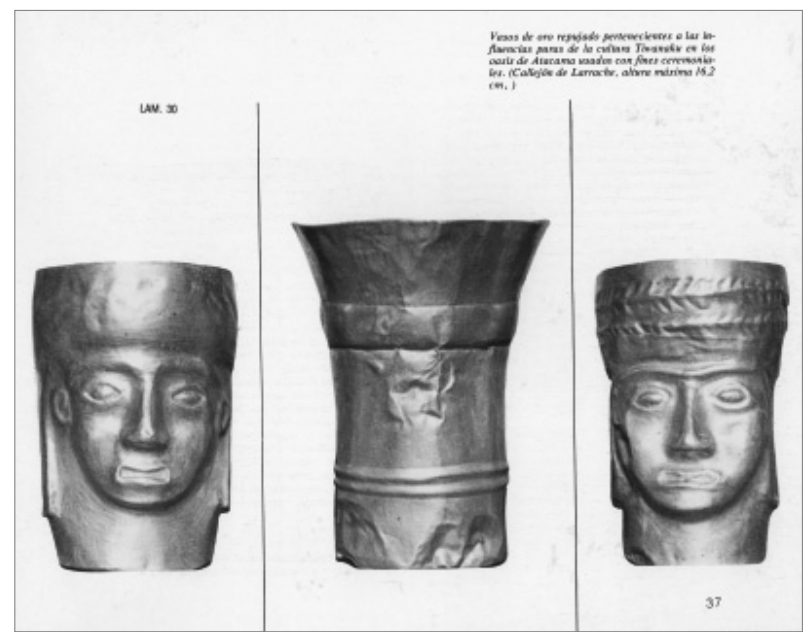

22. Hombres materiales en Cultura Atacameña (1978).

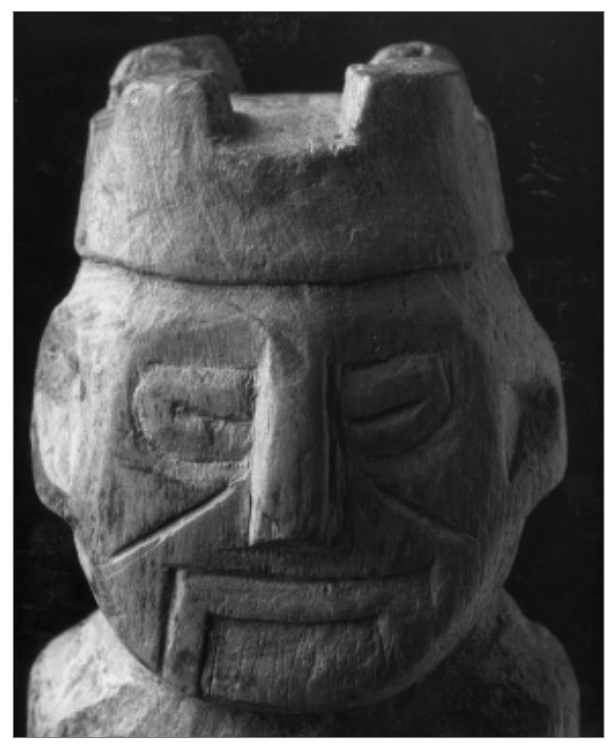

23. Hombres materiales en Pueblos del Desierto, entre el Pacífico y los Andes (2001).

\footnotetext{
$6 \quad$ Véase Bittman, et. al.: 36 y 37; Reyes: 131; Santoro, et. al.: 30, 59, 68, 78, 79, 86, 89, 90 y 91.
} 


\section{Momias: Calaveras, esqueletos y huesos}

La exposición de momias es el más brutal de los reemplazos del significante humano. Se exhibe lo que ha sido velado, su debelación es la suplantación más radical del indígena. La momia es la muerte en vida, no su «representación»-las comunidades indígenas así lo manifiestan, hay que creerles- es la persona en presencia difunta. Nuestros autores al incluir las fotografías de momias nos dejan en claro el ejercicio de sentido de sus imágenes fotográficas, todo "debe», en el lapsus, esquivar a la fotografía del indígena, hasta el extremo de sacarlo de la tierra para mostrarlo en vida. ${ }^{7}$

En la descripción del proceso de momificación que hacen algunos de nuestros autores, está presente la frialdad del patólogo, ya que se reconstruye el proceso con minuciosidad forense, para instalar el signo de la momia con todo su sentido: lo que la momia hizo para llegar a ser lo que es:

Esta práctica involucra un extraordinario conocimiento de la anatomía del cuerpo humano. Así, una vez que un miembro de la comunidad fallecía, procedían a desollarlo y descarnarlo, sacando todos los órganos como pulmones, intestinos, corazón, dejando solo la estructura ósea. No sabemos qué cantidad de tiempo involucraba esta etapa, pero el esqueleto era completamente desarticulado para posteriormente rearmarlo al igual que un puzzle, donde los huesos eran recolocados en su posición anatómica. [...] La cabeza era separada del tronco y procedía también a desprender el cuero cabelludo, guardando la piel en la cara, para ponerla después. Desollada la cabeza completa, dejaban el cráneo limpio, que procedían a cortar en dos, separando la región facial de la calota para extraer la masa encefálica (Santoro, 2001: 40).

Sigue el texto relatando el resto del proceso de momificación, es interesante hacer notar cómo el pormenorizado texto va en apoyo de la imagen, describiéndonos el nacimiento de momia, un extraño parto invertido, un poco, como todo lapsus: «desplazado» (láminas 24 y 25 ).

Véase Santoro, et al., 2001, Capítulo 4, «Las momias negras; Las momias rojas» (40-44) y Bittman, et al., 1975: 24. 


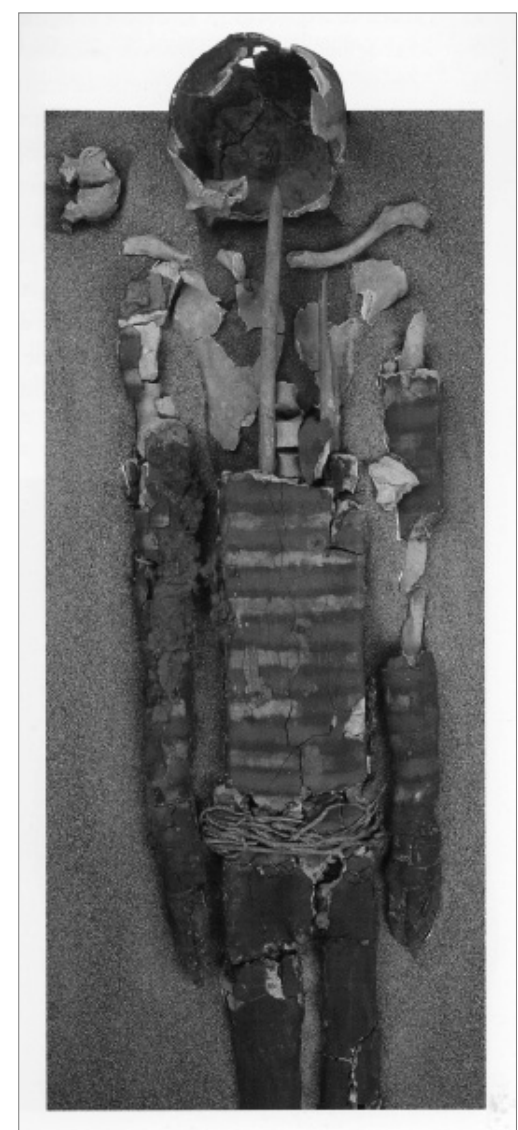

24. Momia en Pueblos del Desierto, entre el Pacífico y los Andes (2001).

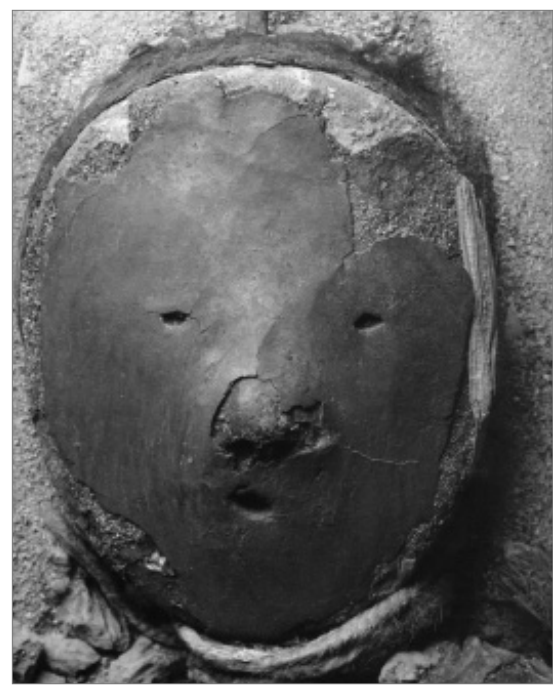

25. Momia en Pueblos del Desierto, entre el Pacífico y los Andes (2001). 


\section{LA TOPOLOGÍA SIGNIFICANTE DEL TEXTO}

Ésta se puede establecer inicialmente por las propias reglas de los autores, sus índices y capítulos, o por las secuencias de los tópicos de sus textos. Diríamos de forma consciente para índices y capítulos o inconsciente para el paradigma sintagmático, o de manera manifiesta o encubierta.

Fotografías y textos se van vinculando en un desarrollo general de las obras de manera secuencial, de los paisajes y los orígenes, hasta la actualidad, sin imágenes del indígena. Es notable que para los indígenas contemporáneos la obra de Bittman et. al. elija el Epílogo, como final del texto o residuo discursivo, sin fotografías.

También en Santoro et al., se elige el último capítulo del libro para la etnografía — «El mundo pos-hispánico: La conquista hispana, indios caciques y españoles; La república y los indios, de indígenas a ciudadanos»-, lo más notable es que el soporte del significante, la hoja de papel, cambia de color, del blanco a un color pastel, además cambia la substancia del significante, que son colores; de blanco a color pastel en clara indicación del lapsus. El soporte del significante fotográfico (y textual), fotografía solo posible, marca que hay un cambio de tópico, pero no es capaz de romper, como todo lapsus, con su automatismo de repetición, Wiederholungszwang, y elimina, "olvida» diría Freud (1996: 9-16), a la imagen del indígena del Desierto, invisibilizándolo.

El desplazamiento en los textos, lugar de la fotografía de la materialidad indígena, puro significante, es el significado robado, la presencia visual del indígena, que se repite en las obras de nuestros autores, "y es esto lo que para nosotros lo confirmará como automatismo de la repetición» (Lacan, 1990: 10).

\section{LOS CUERPOS BORRADOS LAS ALMAS SUPLANTADAS}

From the Spiritual Sky, Such sweet memories have I To the Spiritual Sky

George Harrison, 1973

La sustancia gruesa del desierto, su paisaje deshabitado, sus animales y plantas estilizados, su arquitectura de ruinas monumentales, el hombre hecho objeto en el vestigio arqueológico, impresionan los sentidos del observador, y muy especialmente a los del cronista literario o cuentista, provenientes de la frondosidad vegetal.

Nos relata Salvador Reyes:

Además de armas y utensilios prehistóricos, el Museo encierra una magnífica colección de alfarería atacameña y una sorprendente serie de momias, entre las cuales hay la de un niño sacrificado según un rito incaico; otra envuelta en un curioso tejido; otra con una larga cabellera. El grupo produce una impresión algo escalofriante... (1969: 166).

La imaginación visual fotográfica del Norte Grande, del desierto y el altiplano, para sus constructores chilenos - cronistas, exploradores y etnólogos- se expresa en una ma- 
terialidad misántropa. ¿En qué "perturba» a nuestros autores la presencia improbable de ese indígena en el Desierto, para "olvidarlo», «reprimirlo» en el lapsus? (Freud, 1996).

La imaginería discursiva del Desierto y sus habitantes está conformada por una visualidad que expulsa a la humanidad, donde la materialidad se hace dueña de las imágenes de la obra, escamoteando a la humanidad, sustrayendo, muy especialmente, al indígena, expulsando la presencia del hombre de manera prolija, reemplazándolo por las cosas naturales y culturales, que son el significado para los autores, "su deseo», su Wunsch - paisajes, animales y plantas; marcas de ocupación o tecnologías, y por último momias - instalándolo al indígena proyectado en la cosificación de sus expresiones: en su mundo material del deseo.

\section{REFERENCIAS}

Aldunate, Carlos. (1978). Cultura Mapuche. Santiago: Editorial Gabriela Mistral.

Bittmann, Bente et al. (1978). Cultura atacameña. Santiago: Editorial Gabriela Mistral. Deleuze, Pilles. (2001). La imagen-movimiento. Estudios sobre cine 1. Barcelona: Paidós.

Echavarren, Roberto. (1997). Arte andrógino: estilo versus moda. Buenos Aires: Editorial Colihue.

Freud, Sigmund. (1996). Psicopatología de la vida cotidiana. Madrid: Alianza Editorial.

-. (1993). El malestar de la cultura. Madrid: Alianza Editorial.

Lacan, Jacques. (1990). Escritos 1. México: Siglo XXI Editores.

Laplanche, Jean y J. Pontalis. (2005). Diccionario de psicoanálisis. Buenos Aires: Paidós.

Mason, Peter. (1998). Infelicities, Representations of the Exotic. Londres: The Johns Hopkins University Press.

Mauss, Marcel. (1970). Lo sagrado y lo profano. Barcelona: Seix Barral.

Mayorca Martínez, Pedro. (1972). Costumbres y extinción de los indios del Extremo Austral. Santiago: Imprenta Arancibia Hnos.

Rose, Gillian. (2007). Visual methodologies. Londres: Sage Publications Ltd.

Reyes, Salvador. (1969). Andanzas por el desierto de Atacama. Santiago: Zig-Zag.

Santoro, Calogero, et al. (2001). Pueblos del Desierto, entre el Pacífico y los Andes. Arica: Ediciones Universidad de Tarapacá.

Whorf, Benjamín L. (1971). Lenguaje, pensamiento y realidad. Barcelona: Seix Barral. Žižek, Slavoj. (2005). El acoso de las fantasías. Buenos Aires: Siglo XXI Editores. 